\title{
Muscle-enhancing Behaviors Among Adolescent Girls and Boys
}

AUTHORS: Marla E. Eisenberg, ScD, MPH, a,b Melanie Wall, $\mathrm{PhD},{ }^{\mathrm{c}}$ and Dianne Neumark-Sztainer, PhD, MPH, RD ${ }^{\mathrm{b}}$

aDivision of Adolescent Health and Medicine, Department of Pediatrics, and ${ }^{b}$ Division of Epidemiology \& Community Health, School of Public Health, University of Minnesota, Minneapolis, Minnesota; and 'Departments of Biostatistics and Psychiatry, Columbia University, New York, New York

\section{KEY WORDS}

adolescence, muscle enhancement, steroids, body image

\section{ABBREVIATIONS}

$\mathrm{Cl}$-confidence interval

EAT-Eating and Activity in Teens

$O R$-odds ratio

Dr Eisenberg conceptualized this paper, conducted some data analysis and interpretation, and took primary responsibility for writing; Dr Wall conducted some data analysis and

interpretation, provided critical revision of the manuscript and approved the submitted version; and Dr Neumark-Sztainer led the study from which these data were taken, provided critical revision of the manuscript, and approved the submitted version. www.pediatrics.org/cgi/doi/10.1542/peds.2012-0095

doi:10.1542/peds.2012-0095

Accepted for publication Aug 10, 2012

Address correspondence to Marla Eisenberg, ScD, MPH, Division of Adolescent Health and Medicine, Department of Pediatrics, University of Minnesota, 717 Delaware St SE, Minneapolis, MN 55455. E-mail: eisen012@umn.edu

PEDIATRICS (ISSN Numbers: Print, 0031-4005; Online, 1098-4275).

Copyright (C) 2012 by the American Academy of Pediatrics

FINANCIAL DISCLOSURES: The authors have indicated they have no financial relationships relevant to this article to disclose.

FUNDING: The project described was supported by grant R01HL084064 from the National Heart, Lung, and Blood Institute (principal investigator, Dr Neumark-Sztainer). The content is solely the responsibility of the authors and does not necessarily represent the official views of the National Institutes of Health. Funding by the National Institutes of Health (NIH).
WHAT'S KNOWN ON THIS SUBJECT: Emphasis on muscularity has increased in recent decades. Identifying adolescent populations at risk for unhealthy muscle-enhancing behaviors is of considerable importance, yet recent research in the United States is limited in terms of sample diversity and behaviors of interest.

WHAT THIS STUDY ADDS: Muscle-enhancing behaviors were common for both boys and girls, and rates were higher than reported previously. Adolescents in high school, of Asian background, in overweight/obese BMI categories, and involved in sports reported significantly greater use than other youth.

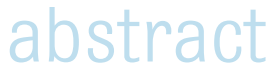

OBJECTIVE: Media images of men and women have become increasingly muscular, and muscle-enhancing techniques are available to youth. Identifying populations at risk for unhealthy muscle-enhancingbehaviors is of considerable public health importance. The current study uses a large and diverse population-based sample of adolescents to examine the prevalence of muscle-enhancing behaviors and differences across demographic characteristics, weight status, and sports team involvement. METHODS: Survey data from 2793 diverse adolescents (mean age $=$ 14.4) were collected at 20 urban middle and high schools. Use of 5 muscle-enhancing behaviors was assessed (changing eating, exercising, protein powders, steroids and other muscle-enhancing substances), and a summary score reflecting use of 3 or more behaviors was created. Logistic regression was used to test for differences in each behavior across age group, race/ethnicity, socioeconomic status, BMI category, and sports team participation.

RESULTS: Muscle-enhancing behaviors were common in this sample for both boys and girls. For example, $34.7 \%$ used protein powders or shakes and $5.9 \%$ reported steroid use. Most behaviors were significantly more common among boys. In models mutually adjusted for all covariates, grade level, Asian race, BMl category, and sports team participation were significantly associated with the use of muscle-enhancing behaviors. For example, overweight (odds ratio $=1.45$ ) and obese (odds ratio $=1.90$ ) girls had significantly greater odds of using protein powders or shakes than girls of average BMl.

CONCLUSIONS: The use of muscle-enhancing behaviors is substantially higher than has been previously reported and is cause for concern. Pediatricians and other health care providers should ask their adolescent patients about muscle-enhancing behaviors. Pediatrics 2012;130:1019-1026 
In recent decades, images of men in the popular media of Western culture have grown increasingly large, lean, and muscular.1,2 The male body has become more visible in advertising, with a stark increase in the proportion of undressed men beginning in the 1980s, ${ }^{3}$ and representations of "ideal" physiques in children's action figures have evolved to be more muscular than even the largest human bodybuilders. ${ }^{2}$ Boys' body dissatisfaction has simultaneously increased, ${ }^{4}$ and research has demonstrated that exposure to images of extremely muscular models contributes to body dissatisfaction and muscle dysmorphia in young men.5-7 Research regarding media images of women has focused almost exclusively on thinness as the cultural ideal for femininity,, 8 but there is some indication that modern media figures combine slenderness with a toned and firm look that was not emphasized in previous generations. ${ }^{10-12}$

Muscle-enhancing behaviors have received considerable attention in the media and popular culture in recent years, as a steady stream of famous male and female athletes have been implicated in legal cases regarding their alleged use of performanceenhancing substances. ${ }^{13-16}$ These cases often play out in the public arena, bringing awareness of muscle-building possibilities to young people around the United States and setting new standards for physical ability and appearance.

Given the emphasis on a muscular body in the media, questions exist about the use of muscle-enhancing behaviors among both athletes and the general population of youth. Existing research has focused largely on male athletes and bodybuilders in whom the prevalence of these behaviors is highest, 17,18 but recent studies with populationbased samples of US youth indicate that $8.0 \%$ of females and $10.2 \%$ of males report using protein supplements, ${ }^{19} 1.0 \%$ of females and $11.0 \%$ of males report using creatine, ${ }^{20}$ and $2.2 \%$ of females and $4.3 \%$ of males report using steroids. ${ }^{21}$ In a populationbased study on adolescents, conducted by our research team over a decade ago (1998-1999), steroid use differed across racial/ethnic groups, with Asian American youth being more likely than other groups to report this behavior.22,23 Adolescents participating in weightrelated sports (defined as a sport in which it is important to stay a certain weight, such as wrestling, gymnastics, or ballet) also had greater odds of steroid use than nonparticipants. ${ }^{24}$ Existing research regarding the prevalence of more general muscle-enhancing behaviors such as changing one's diet or increasing exercise to generate muscle mass has been conducted with non-US samples ${ }^{25-27}$ or boys only, ${ }^{28,29}$ and research into the prevalence of unhealthy muscle-enhancing strategies, including protein powders, steroids, and other substances, requires replication and further exploration. Given the adverse health effects of steroids and other muscle-enhancing substances, 30,31 identifying populations at particular risk and understanding patterns of use hold considerable public health importance.

The current study therefore uses a recent large and diverse populationbased sample of adolescents to examine the prevalence of 5 muscleenhancing behaviors and differences across demographic characteristics, weight status, and sports team involvement.

\section{METHODS}

\section{Study Design and Population}

Data come from EAT 2010 (Eating and Activity in Teens), a study of weight status, dietary intake, physical activity, weight control behaviors, and related factors among adolescents. The sample includes adolescents from 20 public middle schools and high schools in the Minneapolis/St. Paul metropolitan area of Minnesota that serve socioeconomically and racially/ethnically diverse communities. Surveys and anthropometric measures were completed by 2793 adolescents during the 2009-2010 academic year. Trained research staff administered surveys and measured adolescents' height and weight during selected health, physical education, and science classes. All study procedures were approved by the University of Minnesota's Institutional Review Board Human Subjects Committee and by the research boards of the participating school districts. Among adolescents who were at school on the days of survey administration, 96.9\% had parental consent and chose to participate.

\section{Survey and Measures}

The EAT 2010 survey is a 235-item, selfreport instrument assessing a range of factors of potential relevance to weight status and weight-related behaviors among adolescents. ${ }^{4}$ Use of 5 muscleenhancing behaviors was assessed with a question adapted from previous studies 19,25,28: "How often have you done each of the following things in order to increase your muscle size or tone during the past year?" (never, rarely, sometimes, often for each method) and included (a) "Changed my eating," (b) "Exercised more," (c) "Used protein powder or shakes," (d) "used steroids," and (e) "used another musclebuilding substance (such as creatine, amino acids, hydroxyl methylbutyrate [HMB], DHEA, or growth hormone)." For each of the 2 potentially healthy muscle-enhancing behaviors (changing eating and exercise habits), use was dichotomized as those who report the behavior "often" versus all other categories. For each of the 3 unhealthy behaviors (use of protein, steroids, or 
other substances), use was dichotomized as any use versus "never." A summary score indicating the use of any 3 or more behaviors was created from these items as an indicator of severity. The summary score was dichotomized as use of 3 or more behaviors versus fewer to capture a relatively high level of use.

Several demographic and personal characteristics were used as independent variables. Participants reported their gender and school level (grades 6-8 were grouped as middle school; grades 9-12 were grouped as high school). Race/ethnicity was assessed with 1 survey item "Do you think of yourself as (1) white, (2) black or African American, (3) Hispanic or Latino, (4) Asian American, (5) Hawaiian or Pacific Islander, or (6) American Indian or Native American" and respondents were asked to check all that apply. A "mixed/other" race category was created to include those who marked multiple race groups or indicated they were Hawaiian or Pacific Islander, because these groups were too small to permit meaningful analysis as separate categories. The majority (83\%) of Asian participants were Hmong. Socioeconomic status was based primarily on parental education level, defined as the higher level of educational attainment of either parent. An algorithm was developed that also took into account family eligibility for public assistance, eligibility for free or reduced-cost school meals, and employment status of the mother or father. ${ }^{32,33} \mathrm{BMI}$ was calculated by using anthropometric data assessed by EAT 2010 staff. Height was measured without shoes (to the nearest $0.1 \mathrm{~cm}$ ), and weight was measured without heavy outerwear or shoes (to the nearest 0.5 pound). Gender- and age-specific cut points for underweight, normal weight, overweight, and obesity were based on data from the Centers for Disease
Control and Prevention. ${ }^{34}$ Because muscle-enhancing behaviors are often associated with involvement in athletics, sports team participation was assessed by using the question, "During the past 12 months, on how many sports teams did you play?" Participants indicating they played on 1 or more teams were compared with those reporting no sports team involvement.

\section{Data Analysis}

All analyses were stratified by gender a priori because of previously observed differences in the use of each behavior. $\chi^{2}$ tests of association were used to compare the prevalence of each muscle-enhancing behavior (separately) across demographic and personal characteristics.

Logistic regression models in SAS version 9.1 were used to compare the odds of using each muscle-enhancing behavior across demographic characteristics, BMI categories, and sports participation. All covariates were entered simultaneously. To determine if each muscle-enhancing behavior differed by school, we examined for a significant school effect for each outcome and by each gender. These tests were nonsignificant in all but 1 case, protein powder in boys $(P<.01)$; therefore, we did not control for school in the final models in the interest of simplicity.

\section{RESULTS}

The mean age of the study population was 14.4 years $(S D=2.0) ; 46.1 \%$ were in middle school (6th to 8th grades) and $53.9 \%$ were in high school (9th to 12th grades). Participants were equally divided by gender ( $46.8 \%$ male, $53.2 \%$ female). The racial/ethnic backgrounds of the participants were as follows: 18.9\% white, 29.0\% African American or black, $19.9 \%$ Asian American, 16.9\% Hispanic, 3.7\% Native American, and $11.6 \%$ mixed or other. Sixty-two percent were in the lowest 2 categories of economic status, and $57.8 \%$ participated on at least 1 sports team.

Muscle-enhancing behaviors were common among both boys and girls (Table 1). Among boys, more than twothirds reported changing their eating to increase their muscle size or tone, including $11.6 \%$ who did this often, and $>90 \%$ exercised more to increase their muscle mass or tone, including $40.9 \%$ who reported doing so often. Unhealthy behaviors were also prevalent: $34.7 \%$ used protein powders or shakes, $5.9 \%$ reported using steroids, and $10.5 \%$ reported using some other muscle-enhancing substance. Girls were similarly involved, with a large majority changing eating and exercise habits, $21.2 \%$ reporting using protein powders, $4.6 \%$ using steroids, and $5.5 \%$ using other muscle-enhancing substances. Almost $12 \%$ of boys and

TABLE 1 Muscle-enhancing Behaviors Among Boys and Girls During the Past Year

\begin{tabular}{|c|c|c|c|c|c|c|c|c|}
\hline & \multicolumn{2}{|c|}{ Never } & \multicolumn{2}{|c|}{ Rarely } & \multicolumn{2}{|c|}{ Sometimes } & \multicolumn{2}{|c|}{ Often } \\
\hline & $n$ & $\%$ & $n$ & $\%$ & $n$ & $\%$ & $n$ & $\%$ \\
\hline \multicolumn{9}{|l|}{ Boys $(n=1307)$} \\
\hline Change eating & 410 & 31.5 & 312 & 24.0 & 426 & 32.8 & 151 & 11.6 \\
\hline Exercise more & 114 & 8.8 & 146 & 11.3 & 507 & 39.1 & 530 & 40.9 \\
\hline Protein powder/shake & 845 & 65.3 & 208 & 16.1 & 160 & 12.4 & 81 & 6.3 \\
\hline Steroids & 1213 & 94.1 & 36 & 2.8 & 30 & 2.3 & 10 & 0.8 \\
\hline Other muscle-enhancing substances & 1152 & 89.5 & 52 & 4.0 & 52 & 4.0 & 31 & 2.4 \\
\hline \multicolumn{9}{|l|}{ Girls $(n=1486)$} \\
\hline Change eating & 559 & 37.8 & 279 & 18.9 & 462 & 31.2 & 180 & 12.2 \\
\hline Exercise more & 286 & 19.4 & 249 & 16.9 & 539 & 36.5 & 403 & 27.3 \\
\hline Protein powder/shake & 1165 & 78.8 & 193 & 13.1 & 91 & 6.2 & 29 & 2.0 \\
\hline Steroids & 1410 & 95.6 & 48 & 3.3 & 13 & 0.9 & 4 & 0.3 \\
\hline Other muscle-enhancing substances & 1397 & 94.5 & 47 & 3.2 & 24 & 1.6 & 10 & 0.7 \\
\hline
\end{tabular}


$6.2 \%$ of girls reported using 3 or more of the behaviors examined here, indicating a relatively high level of use.

\section{Associations Between}

Muscle-enhancing and

Demographics, BMI, and Sports

\section{Unadjusted Associations}

$\chi^{2}$ tests indicated that rates of use (often for changing eating and exercise; "any" for protein, steroids, and other substances) were significantly higher for boys in comparison with girls $(P<.001)$ for all behaviors, with the exception of changing eating $\left(\chi^{2}=\right.$ $0.2, P=.662)$ and steroid use $\left(\chi^{2}=3.2\right.$, $P=.076$ ). Table 2 shows the percentage of respondents reporting each type of muscle-enhancing behavior in each of the demographic and personal categories, and several significant differences are noted. In particular, those participating on sports teams were significantly more likely to report more muscle-enhancing behaviors than those not involved in sports. For example, the use of 3 or more behaviors was more than twice as high among boys who participated in sports versus nonparticipants (14.1 vs $6.7, \chi^{2}=15.4, P<.001$ ).

\section{Adjusted Associations}

In models mutually adjusted for all covariates, several characteristics were significantly associated with the use of muscle-enhancing behaviors. As shown in Table 3, high school boys had significantly greater odds of using protein powders/shakes (odds ratio $[0 R]=1.70$, confidence interval $[\mathrm{Cl}]=$ 1.30-2.21) and other muscle-enhancing substances $(\mathrm{OR}=1.73, \mathrm{Cl}=1.12-2.66)$ than those in middle school. Asian boys (primarily Hmong) had elevated odds of steroid use $(\mathrm{OR}=3.51, \mathrm{Cl}=1.13$ 10.92) compared with whites. BMI was significantly associated with changing eating, protein powders, and steroid use. Overweight and obese boys were more likely to report these behaviors than boys of average BMI. Sports team participation was significantly associated with all muscle-enhancing behaviors assessed here, with the exception of steroid use. For example, the odds of using protein powders or shakes were $2.05(\mathrm{Cl}=2.11-3.61)$ for boys on at least 1 sports team in comparison with those not on any sports teams.

Similar associations were found among girls (Table 3). Those in high school had lower odds of protein powders/shakes than those in middle school. BMI category was significantly associated with changing eating, exercising, and protein powders. Asian girls stood out as having the highest odds of using steroids $(\mathrm{OR}=3.37, \mathrm{Cl}=1.29-8.80$ ) and other muscle-enhancing substances $(0 \mathrm{R}=2.76, \mathrm{Cl}=1.12-6.82)$. As with boys, girls who are obese (or overweight, in the case of protein use) had significantly elevated odds of reporting these behaviors than those of average weight. Sports team participation was positively associated with changing eating, exercising, and using protein powders/shakes.

\section{DISCUSSION}

Results from the current study reveal that behaviors aimed at increasing muscle size or tone are extremely common: almost all students report doing at least 1 behavior with this as the goal, and up to one-third reported the use of unhealthy methods, such as taking steroids or other muscle-enhancing substances. Muscle enhancement is common and was particularly high among boys and those involved in sports teams, as seen previously. ${ }^{19-21,23,24,29}$ However, use was not limited to these groups. This finding suggests that, in addition to a "thin ideal" and focus on leanness, 35,36 muscularity is an important component of body satisfaction for both genders.

The current study found reports of muscle-enhancing behaviors (ie, steroids and other substances) to be higher than other recent research with US youth. 20,21,37 These differences could be due to the demographic makeup of the different samples. The current study was almost $20 \%$ Asian youth (primarily Hmong), who reported higher rates of use of the muscleenhancing behaviors examined here (compared with other racial groups in this study), but had lower representation in other recent studies.20,21,37 Similarly, our sample was largely of lower economic status, a group that has not been separately reported on in earlier work. Future research including a wider variety of muscleenhancing behaviors and using a more diverse and nationally representative sample of young people is needed to replicate the current study's findings.

This study's findings regarding associations between higher BMI and the use of muscle-enhancing behaviors are subject to possible alternate interpretations. Specifically, high BMI may reflect muscle mass rather than adiposity (particularly in males), which may result from use of the behaviors of interest. However, existing research has shown that overweight and obese young people engage in a variety of weight control and body change strategies at greater rates than their average-weight peers, ${ }^{37-39}$ which suggests that weight status may indeed contribute to the adoption of the muscle-enhancing behaviors examined here. Further research with more comprehensive measures of body weight and composition is needed to disentangle this association.

Interestingly, this study did not find significant clustering of muscleenhancing behaviors within schools. Rather than being driven by a particular school sports team coach or other features of a school's social landscape, this diffusion suggests that muscleenhancing behaviors are widespread 


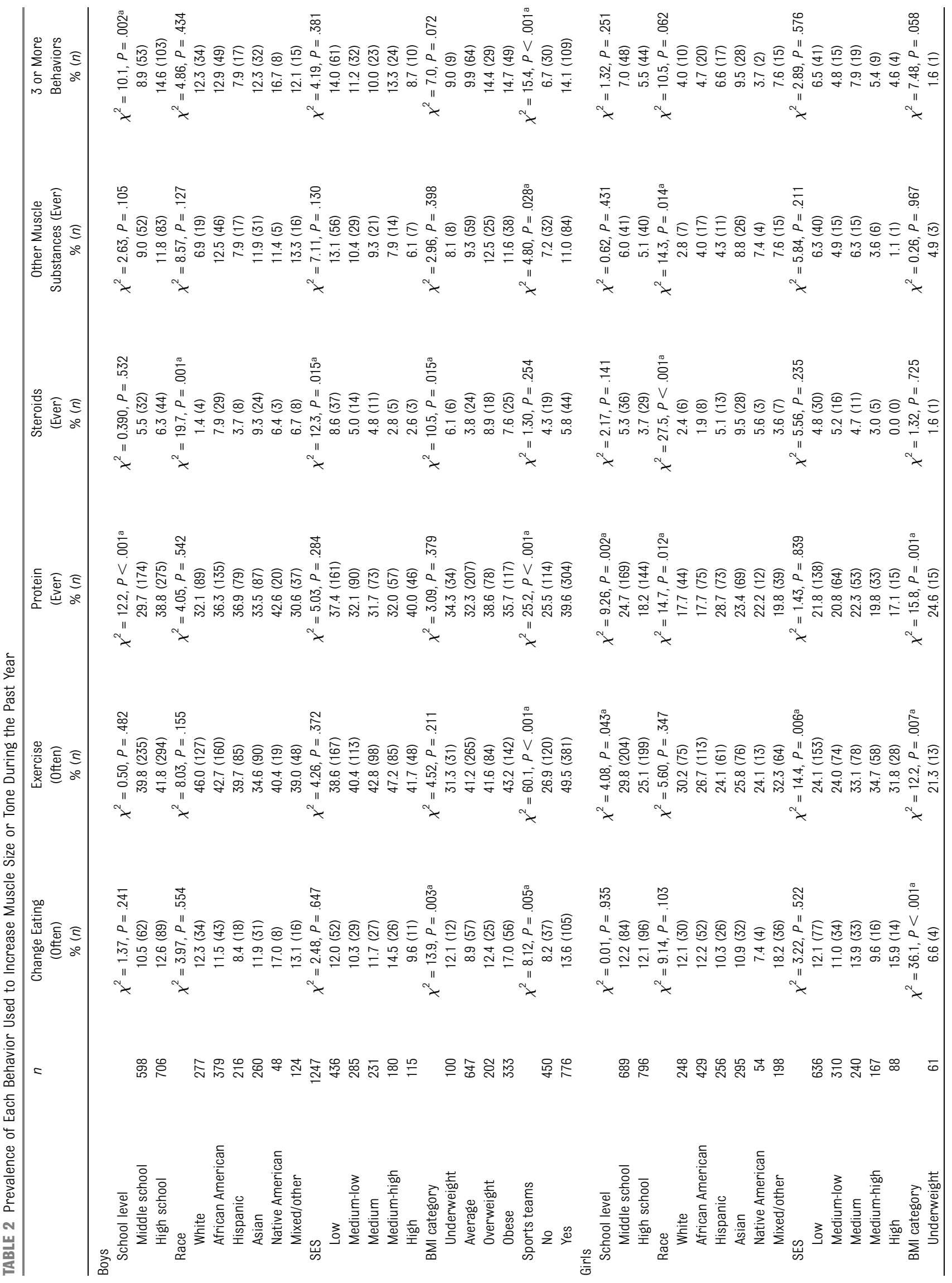




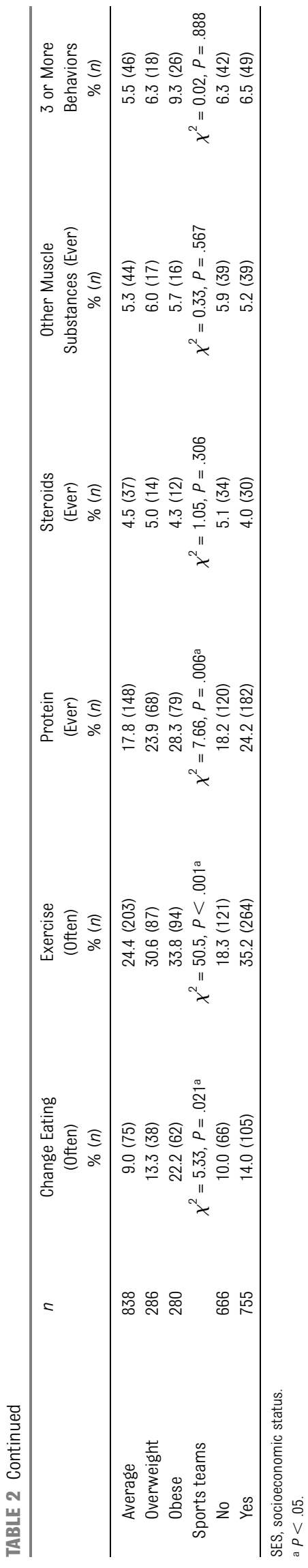

and influenced by factors beyond school, likely encompassing social and cultural variables such as media messages and social norms of behavior more broadly. As with the large body of literature investigating an array of influences on body dissatisfaction relating to thinness, continued research into media portrayals of muscularity, ${ }^{5-7}$ as well as interpersonal interactions such as weight- and shape-teasing, or sharing muscle-enhancing substances among peers may be promising avenues for understanding the parallel phenomenon of dissatisfaction with regard to muscularity and unhealthy behaviors aimed at muscle enhancement.

Data for the current study come from a single state and, as such, may not be representative of muscle-enhancing behaviors elsewhere in the United States or in other countries. In addition, all measures were self-reported and included the use of illegal substances, which may have led to underreporting. Finally, more detailed measures of muscle-enhancing behaviors and body weight were not assessed. Specifically, we do not have data regarding whether respondents who changed their eating adopted healthy or unhealthy dietary changes, and use of several other muscle-enhancing substances were assessed in a single item. Similarly, the measure of BMl does not distinguish adiposity from weight because of muscle mass; it is therefore possible that associations seen here were due to increased muscle resulting from the behaviors under study. Future research should include other assessments of body weight and composition to further address this question.

However, the large and diverse sample from multiple schools permitted statistically valid analyses of relatively uncommon behaviors and smaller groups not typically considered in epidemiological research (eg, certain racial groups) and allowed for an examination of clustering by school. Finally, this study used 5 measures of muscle-enhancing behavior spanning the range from general health behaviors (eg, exercising) to extremely unhealthy behaviors (eg, steroid use), which provides a more comprehensive picture of muscle-enhancing efforts among a US sample of male and female youth than has been available previously.

\section{CONCLUSIONS}

Pediatricians and other health care providers should ask their adolescent patients about muscle-enhancing behaviors. Conceptualization of these behaviors should include frequent use of seemingly healthy behaviors (eg, changing eating and exercising) done with the goal of increasing muscle mass or tone. Although these may be beneficial, compulsive or excessive use is cause for concern, ${ }^{37}$ because they may be a precursor to the development of more severe and unhealthy behaviors over time. Health care providers should counsel adolescent patients about appropriate exercise, general nutrition, and the lack of efficacy and potential dangers of muscle-enhancement products. Given the observed associations with sports participation, sports physicals may present a particularly salient opportunity to initiate these conversations.

Prevention and intervention programs targeting muscle-enhancing behaviors among youth are needed for both boys and girls and should include parents, teachers, and coaches as well as youth themselves. Broadening existing body image programs to address muscularity as well as thinness would be an appropriate and cost-effective approach. Although it is appropriate to promote physical activity in youth, which may have desirable benefits in 
TABLE 3 Odds Ratio (and 95\% Cl) of Using Each Behavior to Increase Muscle Size or Tone During the Past Year, Mutually Adjusted for All Variables Shown

\begin{tabular}{|c|c|c|c|c|c|c|}
\hline & Change Eating (Often) & Exercise (Often) & Protein (Ever) & Steroids (Ever) & Other Muscle Substances (Ever) & 3 or More Behaviors \\
\hline \multicolumn{7}{|l|}{ Boys } \\
\hline \multicolumn{7}{|l|}{ School level } \\
\hline Middle school & - & - & - & - & - & - \\
\hline High school & $1.27(0.87-1.85)$ & $1.05(0.81-1.34)$ & $1.70(1.30-2.21)^{\mathrm{a}}$ & $1.47(0.83-2.62)$ & $1.73(1.12-2.66)^{\mathrm{a}}$ & $2.08(1.39-3.12)^{\mathrm{a}}$ \\
\hline \multicolumn{7}{|l|}{ Race } \\
\hline White & - & - & - & - & - & - \\
\hline African American & $0.88(0.52-1.51)$ & $0.78(0.54-1.12)$ & $1.00(0.69-1.46)$ & $2.63(0.85-8.07)$ & $1.13(0.59-2.13)$ & $0.74(0.43-1.28)$ \\
\hline Hispanic & $0.50(0.25-0.99)^{\mathrm{a}}$ & $0.75(0.49-1.13)$ & $1.18(0.77-1.81)$ & $1.23(0.34-4.46)$ & $0.70(0.33-1.52)$ & $0.42(0.21-0.83)^{\mathrm{a}}$ \\
\hline Asian & $1.05(0.59-1.88)$ & $0.72(0.48-1.08)$ & $1.14(0.75-1.72)$ & $3.51(1.13-10.92)^{a}$ & $1.53(0.78-2.97)$ & $0.94(0.52-1.71)$ \\
\hline Native American & $1.18(0.43-3.19)$ & $0.97(0.47-2.00)$ & $1.75(0.84-3.61)$ & $1.98(0.33-11.91)$ & $1.06(0.28-3.98)$ & $1.03(0.35-3.01)$ \\
\hline Mixed/other & $1.07(0.53-2.16)$ & $0.75(0.46-1.22)$ & $0.89(0.53-1.49)$ & $2.64(0.71-9.90)$ & $1.58(0.72-3.48)$ & $0.91(0.44-1.89)$ \\
\hline SES & $1.01(0.87-1.17)$ & $1.05(0.95-1.16)$ & $1.04(0.94-1.16)$ & $0.74(0.57-0.95)^{\mathrm{a}}$ & $0.86(0.72-1.01)$ & $0.92(0.79-1.07)$ \\
\hline \multicolumn{7}{|l|}{ BMI category } \\
\hline Underweight & $1.64(0.83-3.23)$ & $0.71(0.43-1.16)$ & $1.18(0.73-1.92)$ & $2.13(0.74-6.11)$ & $1.12(0.50-2.48)$ & $1.17(0.55-2.49)$ \\
\hline Average & - & - & - & - & - & - \\
\hline Overweight & $1.27(0.73-2.23)$ & $1.02(0.71-1.46)$ & $1.61(1.13-2.31)^{\mathrm{a}}$ & $3.23(1.53-6.83)^{a}$ & $1.67(0.96-2.89)$ & $1.70(1.00-2.88)^{a}$ \\
\hline Obese & $2.26(1.47-3.47)^{\mathrm{a}}$ & $1.31(0.98-1.77)$ & $1.21(0.89-1.65)$ & $2.83(1.43-5.60)^{a}$ & $1.45(0.89-2.36)$ & $1.95(1.25-3.04)^{\mathrm{a}}$ \\
\hline \multicolumn{7}{|l|}{ Sports teams } \\
\hline No & - & - & - & - & - & - \\
\hline Yes & $1.84(1.21-2.79)^{a}$ & $2.76(2.11-3.61)^{\mathrm{a}}$ & $2.05(1.55-2.71)^{\mathrm{a}}$ & $1.44(0.79-2.60)$ & $1.66(1.06-2.62)^{a}$ & $2.47(1.57-3.87)^{\mathrm{a}}$ \\
\hline \multicolumn{7}{|l|}{ Girls } \\
\hline \multicolumn{7}{|l|}{ School level } \\
\hline Middle school & - & - & - & - & - & - \\
\hline High school & $1.00(0.72-1.41)$ & $0.85(0.66-1.09)$ & $0.76(0.58-0.99)^{a}$ & $0.75(0.44-1.25)$ & $0.83(0.52-1.35)$ & $0.76(0.49-1.19)$ \\
\hline \multicolumn{7}{|l|}{ Race } \\
\hline White & - & - & - & - & - & - \\
\hline African American & $0.91(0.54-1.55)$ & $1.00(0.68-1.47)$ & $1.04(0.66-1.62)$ & $0.74(0.24-2.22)$ & $1.19(0.47-3.06)$ & $1.21(0.54-2.74)$ \\
\hline Hispanic & $0.83(0.46-1.52)$ & $0.97(0.63-1.51)$ & $1.79(1.12-2.85)^{\mathrm{a}}$ & $1.84(0.65-5.17)$ & $1.34(0.49-3.67)$ & $1.75(0.75-4.08)$ \\
\hline Asian & $0.97(0.54-1.74)$ & $1.20(0.78-1.82)$ & $1.49(0.93-2.38)$ & $3.37(1.29-8.80)^{\mathrm{a}}$ & $2.76(1.12-6.82)^{a}$ & $2.54(1.14-5.64)^{a}$ \\
\hline Native American & $0.39(0.11-1.36)$ & $0.82(0.39-1.72)$ & $1.33(0.62-2.83)$ & $1.99(0.46-8.58)$ & $2.49(0.68-9.17)$ & $0.85(0.18-4.13)$ \\
\hline Mixed/other & $1.45(0.82-2.57)$ & $1.14(0.73-1.77)$ & $1.09(0.66-1.81)$ & $0.96(0.28-3.27)$ & $2.10(0.79-5.57)$ & $1.72(0.72-4.11)$ \\
\hline SES & $1.02(0.88-1.17)$ & $1.13(1.02-1.09)^{a}$ & $0.99(0.89-1.11)$ & $0.90(0.70-1.15)$ & $0.90(0.72-1.11)$ & $1.06(0.87-1.28)$ \\
\hline \multicolumn{7}{|l|}{ BMI category } \\
\hline Underweight & $0.63(0.22-1.79)$ & $0.70(0.37-1.35)$ & $1.47(0.79-2.75)$ & $0.38(0.05-2.85)$ & $0.98(0.29-3.30)$ & $0.26(0.04-1.95)$ \\
\hline Average & - & - & - & - & - & - \\
\hline Overweight & $1.26(0.80-1.97)$ & $1.34(0.97-1.84)$ & $1.45(1.03-2.05)^{\mathrm{a}}$ & $1.25(0.64-2.43)$ & $1.12(0.60-2.08)$ & $1.10(0.61-2.00)$ \\
\hline Obese & $2.76(1.86-4.08)^{\mathrm{a}}$ & $1.53(1.11-2.10)^{\mathrm{a}}$ & $1.90(1.36-2.66)^{\mathrm{a}}$ & $1.03(0.51-2.10)$ & $1.04(0.55-1.97)$ & $1.78(1.05-3.03)^{\mathrm{a}}$ \\
\hline \multicolumn{7}{|l|}{ Sports teams } \\
\hline No & - & - & - & - & - & - \\
\hline Yes & $1.44(1.02-2.04)^{\mathrm{a}}$ & $2.30(1.77-2.98)^{\mathrm{a}}$ & $1.46(1.11-1.92)^{\mathrm{a}}$ & $0.89(0.52-1.53)$ & $0.93(0.57-1.51)$ & $1.06(0.67-1.66)$ \\
\hline
\end{tabular}

SES, socioeconomic status; - , reference category

a $P<.05$

terms of health and body composition, care should be taken to emphasize moderation in behaviors and to focus on skill development, fitness, and general health rather than development of a muscular appearance. Significant differences found in select race categories suggest that prevention programs might be strengthened by incorporating culturally relevant messages and targeting communities where rates are highest. Similarly, although muscle enhancing behaviors were reported by young people in organized sports as well as those not on teams, prevention activities targeting coaches, sports teams, and their parents are likely to be beneficial, given the significantly higher prevalence of these behaviors among sports participants.

\section{REFERENCES}

1. Leit RA, Pope HG Jr, Gray JJ. Cultural expectations of muscularity in men: the evolution of playgirl centerfolds. Int J Eat Disord. 2001;29(1):90-93
2. Pope HG Jr, Olivardia R, Gruber A, Borowiecki J. Evolving ideals of male body image as seen through action toys. Int J Eat Disord. 1999;26(1):65-72
3. Pope HG Jr, Olivardia R, Borowiecki JJ III, Cohane GH. The growing commercial value of the male body: a longitudinal survey of advertising in women's magazines. 
Psychother Psychosom. 2001;70(4):189192

4. Neumark-Sztainer $D$, Wall $M$, Larson $N$, Story M, Fulkerson JA, Eisenberg ME. Secular trends in weight status and weightrelated attitudes and behaviors in adolescents from 1999-2010. Prev Med. 2012;54 (1):77-81

5. Leit RA, Gray JJ, Pope HG Jr. The media's representation of the ideal male body: a cause for muscle dysmorphia? Int J Eat Disord. 2002;31(3):334-338

6. Daniel S, Bridges SK. The drive for muscularity in men: media influences and objectification theory. Body Image. 2010;7(1): 32-38

7. Lorenzen LA, Grieve FG, Thomas A. Exposure to muscular male models decreases men's body satisfaction. Sex Roles. 2004;51(1112):743-748

8. Andrist LC. Media images, body dissatisfaction, and disordered eating in adolescent women. MCN Am J Matern Child Nurs. 2003;28(2):119-123

9. Hogan MJ, Strasburger VC. Body image, eating disorders, and the media. Adolesc Med State Art Rev. 2008;19(3):521-546, x-xi

10. Grogan S. Body Image: Understanding Body Dissatisfaction in Men, Women, and Children. 2nd ed. London, England: Routledge; 2008

11. Gruber AJ. A more muscular female body ideal. In: Thompson JK, Cafri G, eds. The Muscular Ideal Psychological, Social, and Medical Perspectives. Washington, DC: American Psychological Association; 2007 . 217-234

12. Homan K. Athletic-ideal and thin-ideal internalization as prospective predictors of body dissatisfaction, dieting, and compulsive exercise. Body Image. 2010;7(3):240245

13. Associated Press. Barry Bonds indicted. November 15, 2007. Available at: www. sfgate.com/flat/archive/2007/11/15/news/ archive/2007/11/15/state/n141013S18.html. Accessed October 5, 2011

14. Wikipedia. List of doping cases in sport. Available at: en.wikipedia.org/wiki/List_of doping_cases_in_sport\#cite_note-61 Accessed October 5, 2011

15. Baum B. Report positive doping test for Marion Jones. USA Today. August 19, 2006. Available at: http://usatoday30.usatoday.com/ sports/olympics/summer/track/2006-08- 18-marion-jones-doping-report_x.htm. Accessed October 5, 2011

16. Puma M. Not the size of the dog in the fight. Available at: espn.go.com/classic/biography/ s/Alzado_Lyle.html. Accessed October 5, 2011

17. Metzl JD, Small E, Levine SR, Gershel JC Creatine use among young athletes. Pediatrics. 2001;108(2):421-425

18. Smith J, Dahm DL. Creatine use among a select population of high school athletes. Mayo Clin Proc. 2000;75(12):1257-1263

19. Field AE, Austin SB, Camargo CA Jr, et al. Exposure to the mass media, body shape concerns, and use of supplements to improve weight and shape among male and female adolescents. Pediatrics. 2005;116(2). Available at: www.pediatrics.org/coii/content/ full/116/2/e214

20. Johnston LD, O'Malley PM, Bachman JG, Schulenberg JE, eds. Secondary School Students. Ann Arbor, MI: Institute for Social Research, The University of Michigan; 2010. Monitoring the Future. National Survey Results on Drug Use, 1975-2010; vol 1

21. Centers for Disease Control and Prevention. Youth Risk Behavior SurveillanceUnited States, 2009. MMWR Morb Mortal Wkly Rep. 2010;59(SS-5):1-142

22. vandenBerg P, Neumark-Sztainer D, Cafri G, Wall M. Steroid use among adolescents: longitudinal findings from Project EAT. Pediatrics. 2007;119(3):476-486

23. Irving LM, Wall M, Neumark-Sztainer $D$, Story M. Steroid use among adolescents: findings from Project EAT. J Adolesc Health. 2002;30(4):243-252

24. Vertalino M, Eisenberg ME, Story M, NeumarkSztainer D. Participation in weight-related sports is associated with higher use of unhealthful weight-control behaviors and steroid use. J Am Diet Assoc. 2007;107 (3): 434-440

25. McCabe MP, Ricciardelli LA. Body image and body change techniques among young adolescent boys. Eur Eat Disord Rev. 2001;9 (5):335-347

26. McCabe MP, Ricciardelli LA. Parent, peer, and media influences on body image and strategies to both increase and decrease body size among adolescent boys and girls. Adolescence. 2001;36(142):225-240

27. McCreary DR, Sasse DK. An exploration of the drive for muscularity in adolescent boys and girls. J Am Coll Health. 2000;48(6): 297-304
28. Smolak L, Murnen SK, Thompson JK. Sociocultural influences and muscle building in adolescent boys. Psychol Men Masc. 2005;6(4):227-239

29. Cafri G, van den Berg P, Thompson JK. Pursuit of muscularity in adolescent boys: relations among biopsychosocial variables and clinical outcomes. J Clin Child Adolesc Psychol. 2006;35(2):283-291

30. Fernandez MMF, Hosey RG. Performanceenhancing drugs snare nonathletes, too. J Fam Pract. 2009;58(1):16-23

31. National Institute on Drug Abuse Research Report Series. Anabolic Steroid Abuse. NIH Publication 00-3721. Available at: www. drugabuse.gov/sites/default/files/rrsteroids 0.pdf. Accessed September 1, 2011

32. Breiman L, Friedman J, Olshen R, Stone C. Classification and Regression Trees. Belmont, CA: Wadsworth International Group; 1984

33. Neumark-Sztainer D, Story M, Hannan PJ, Croll J. Overweight status and eating patterns among adolescents: where do youths stand in comparison with the healthy people 2010 objectives? Am J Public Health 2002;92(5):844-851

34. Kuczmarski RJ, Ogden CL, Grummer-Strawn LM, et al. CDC growth charts: United States. Adv Data. 2000; (314):1-27

35. Stice E. Risk and maintenance factors for eating pathology: a meta-analytic review. Psychol Bull. 2002;128(5):825-848

36. Stice E, Whitenton K. Risk factors for body dissatisfaction in adolescent girls: a longitudinal investigation. Dev Psychol. 2002;38 (5):669-678

37. Cafri G, Thompson JK, Ricciardelli L, McCabe M, Smolak L, Yesalis C. Pursuit of the muscular ideal: Physical and psychological consequences and putative risk factors. Clin Psychol Rev. 2005;25(2):215239

38. Boutelle K, Neumark-Sztainer D, Story M, Resnick M. Weight control behaviors among obese, overweight, and nonoverweight adolescents. J Pediatr Psychol. 2002;27 (6):531-540

39. Neumark-Sztainer D, Story M, Hannan PJ, Perry CL, Irving LM. Weight-related concerns and behaviors among overweight and nonoverweight adolescents: implications for preventing weight-related disorders. Arch Pediatr Adolesc Med. 2002;156 (2): 171-178 